\title{
RECONFIGURABILITY APPROACH IN MANUFACTURE OF MOULDS AND DIES
}

\author{
*A.O. Oke ${ }^{1}$, K. Abou-El-Hossein ${ }^{2}$ and N. J. Theron ${ }^{3}$ \\ ${ }^{1,3}$ Department of Mechanical and Aeronautical Engineering, University of Pretoria, \\ Pretoria, South Africa, e-mail: okekola@yahoo.com; Nico.Theron@up.ac.za \\ ${ }^{2}$ Department of Mechatronics, Nelson Mandela Metropolitan University, Port Elizabeth, \\ South Africa, e-mail: Khaled.Abou-El-Hossein@nmmu.ac.za \\ *Corresponding author, e-mail : okekola@yahoo.com
}

Key words: Mould; Die; Manufacturing system; Reconfigurability

\begin{abstract}
Manufacturing of moulds and dies based on the rigid and traditional arrangement of dedicated workstations in a production system can no more stand the test of time. The dynamic and competitive nature of the market is compelling managements in the industry to look for a manufacturing system that (1) will ensure high quality product, (2) will pave way for a quick changeover to a new setup to be able to accommodate the new products, (3) will ensures short lead times in product/process changeover, and (4) that will make its product come out at a relatively low cost. An emerging strategy that might enable industries to cope with the rapidly changing product specifications is based on reconfiguring the manufacturing systems. A manufacturing strategy that is based on reconfiguration of the manufacturing systems may help accommodate emergent product changes in short periods at the lowest possible costs by combining certain levels of flexibility and customised automation. In this paper the principles of reconfigurability is being considered for mould and die making industry.
\end{abstract}

\section{INTRODUCTION}

A mould is the matrix or cavity, in which molten substance is poured to create a given shape and form when the substance cools down, solidifies and hardens. On the other hand a die is a specialized tool used for deformation of metal in order to make it conform to a predetermined shape thereby giving rise to variety of products and components. Several products that are encountered in our daily lives, ranging from metal spare parts to automotive bodies are product of mould and die. Mould or dies are the common terms used to describe the tooling used to produce plastic parts in moulding; it is also used to produce metal parts. The production of moulds and dies has become intensive because this kind of tooling offers reduced cost and large diversity in the shapes of end products. Therefore, mould and dies are usually used in the conditions of mass production where time-to-market might be a critical factor for the product success. The manufacturing industry of tool 
making is characterised by the huge variety of mould (or die) components, especially the endless versions of possible shapes of mould cavities (or die cavities and punches). The standard mould and die components such as the pins, blocks and guides are also characterised by their short lifecycle and big range of variety in terms of sizes and performance requirements. Hence, this factor makes the customised type of flexibility of manufacturing systems more suitable for tooling industry than either fully flexible or dedicated manufacturing systems. The fabrication of mould and die components and the creation of their cavities are achieved by using well established technologies and experiences. However, each mould or die is specified by their geometric features and different combinations of various processing methods may be required, which means completely different machine setups and system reconfigurations. Therefore, for tool and mould making industry, a great level of adaptability and reconfigurability of the manufacturing systems is always desired.

Ideally the engineering design of mould and dies consists of [1]: (a) establishing the kinematic relationships (shape, velocities, strain rates, strains) between the incoming material and the shaped product, i.e. predicting material flow, (b) establishing the limit of productivity, i.e. determining whether it is possible to shape the part without surface or internal failure, and (c) predicting the forces and stresses necessary to execute the shaping operation so that tooling and equipment can be designed and selected. Various mould and die manufacturing techniques are available; in fact the list may be endless as new fabrication methods are always emerging. The most widely used ones are the conventional machining, hobbing, high speed machining, electro-chemical machining, electrical discharge machining, selective laser sintering, etc. The major machines needed for mould and die fabrication are conventional cutting machines, lathe machines, milling machines, drilling machines, boring machine, grinding machines, polishing machines and non-conventional machine tools like the EDM, ECM, HSM, plasma torch, ultrasonic flow polishing machine and other form of conventional polishing machines. Particular preference is placed on the reconfigurability of these machines.

\section{NEED FOR RECONFIGURABILITY IN MOULD AND DIES MANUFACTURE}

In the present world economy, demand for products is unpredictable; the market is highly competitive, dynamic and customer-driven [2]. Customers' demands keep on growing wider apart on daily basis. By the nature of the traditional dedicated manufacturing system (DMS), any slight change in product design may make further production of the new product on the existing production line difficult if not impossible. This is because, DMS, by its design, is made rigid to enhance mass production for profitable and cost-effective purposes. Therefore, survival of companies in a dynamic market scenario calls for an effective and efficient means of promptly responding to any slight change in product demand. Flexible manufacturing system (FMS) was the next option that should come to mind due to the shortcomings of the DMS, but it also has its own shortcomings which make it non- 
productive. The low throughput, high equipment cost due to redundant flexibility and complexity in the design of FMS are the great disadvantages that make it not to be a ready replacement of DMS. Therefore, it is necessary to take into account different manufacturing strategies such as reconfigurable manufacturing in order to ensure a continuous and undisturbed production in the tooling industry

\section{RECOFIGURABILITY OF MANUFACTURING SYSTEM}

Reconfigurability as defined by NSF Engineering Research Centre for Reconfigurable Manufacturing Systems defined the term as the ability to adjust the production capacity and functionality of a manufacturing system to new circumstances through re-arrangement or change of the system's components [3]. From these three given definitions and others [4, 5], it could be deducted that the major objective of reconfigurability is to achieve "exactly the capacity and functionality required and exactly when needed". Reconfigurability is achieved by accomplishing the following six basic characteristics [2]: modularity, scalability, integrability, convertibility, diagnosibility, and customisation. According to Koren et al. [6] Modularity, integrability, and diagnosibility reduce the reconfiguration time and effort while customization, scalability and convertibility reduce the cost of maintenance, the cost of the system and consequently the cost of production. Therefore, for a system to be reconfigurable, these key characteristics must be embedded in it.

\section{PROBLEM STATEMENT AND PROPOSED WORK}

Preliminary thought about the intended reconfigurable manufacturing system for mould and die making is shown in Figure 1. The proposed reconfigurable manufacturing system for mould and die making comprises two subsystems: one for standard mould and die components, and the other for non-standard component that will be in direct contact with the product. The system which, thus, will be responsible for mainly two part families, consists of a reconfigurable lathe machine, a reconfigurable milling machine (which can be reconfigured to perform boring operation), a reconfigurable high speed machining centre, a robot, an EDM, a jig grinder, a reconfigurable noncontact optical inspection machine and a heat treatment section. The proposed material handling system is automatic guided vehicle (AGV). However, the machine arrangement shown in the sketch is not yet the optimum one; whatever, the arrangement of the proposed system must address a certain level of reconfigurability. However, this preliminary sketch will be further refined based on the ongoing research. 


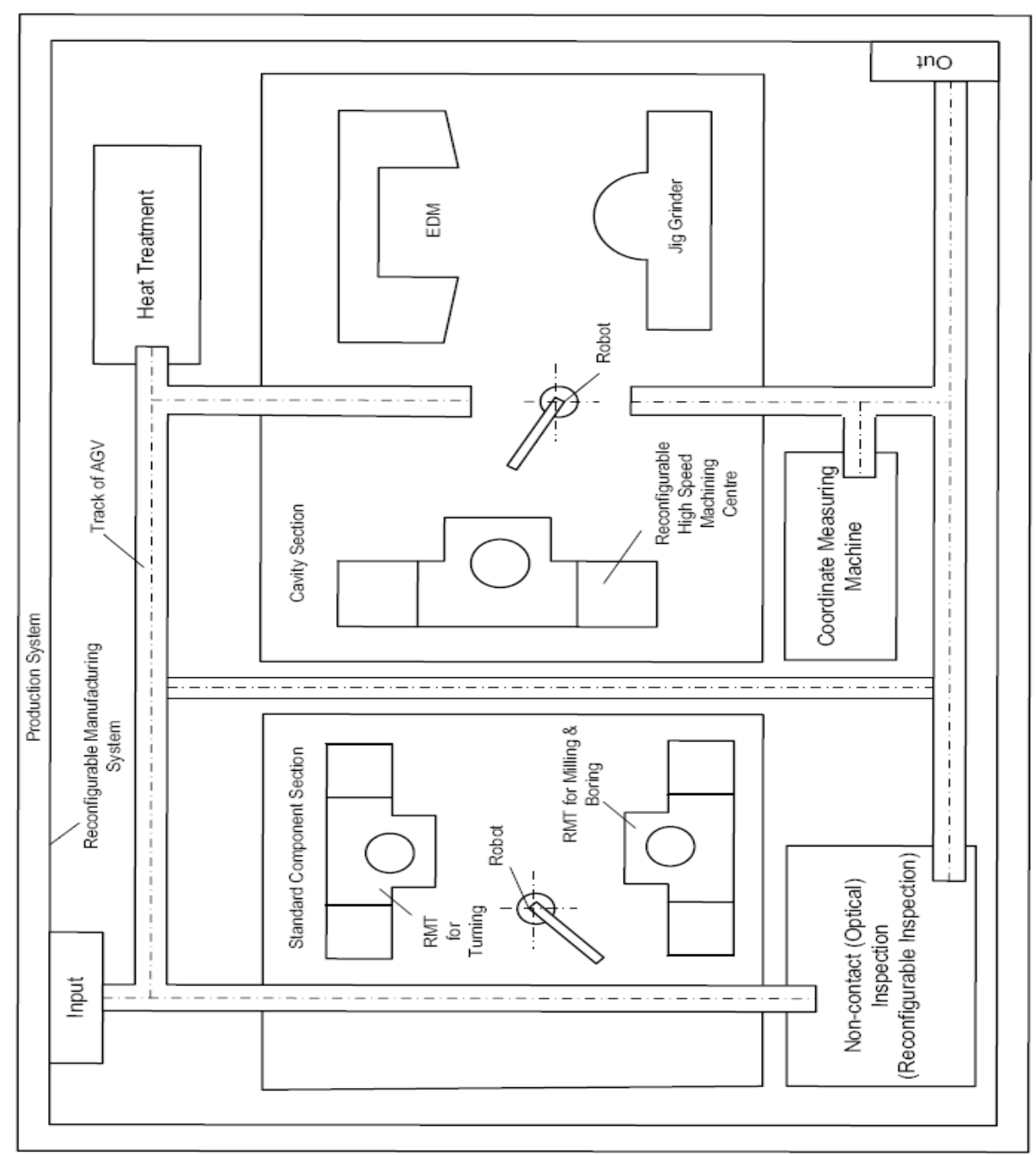

Fig. 1: Schematic of proposed RMS for mould and die making

\section{REALISATION OF THE PRINCIPLES OF RECONFIGURABILITY IN THE PROPOSED SYSTEM}

The grammatical meaning of configuration is "the arrangement (or the process of making the arrangement) of the parts that make up a whole". Therefore reconfigurability is simply the ability of rearranging and/or changing manufacturing elements aimed at adjusting to new environment, introduction of new product and new technological changes [7]. Therefore for reconfigurability to be realised in a mould and die manufacturing system, certain criteria have to be established, some these criteria are considered here.

To achieve the desired reconfigurability in the manufacturing system, features to be created in the mould cavity are grouped into part families; appropriate machines for each feature are identified and grouped into machine cells. Then intracellular machine layout and inter cell layout are performed using the method presented by Ahi et al. [8] and then the process can be planned using the technique presented by Ciurana et al. [9] in which a model for integrating process planning and production and control in machining process was worked out. Their proposed model is a good tool for integrating 
scheduling into CAPP. If there is any change in the product, the corresponding change in mould cavity features to produce the new product will be identified. Then the reconfigurable process planning technique proposed by Azab and ElMaraghy [10] can be applied. By this technique the master plan of the initial part family is first retrieved, and then this is followed by the manipulation of feature precedent graph (FPG) and their associated structures. The result gives a new machine arrangement which will be used to effect reconfiguration on the system. To be able effect these form of reconfigurations, the following recommendations are to be complied with while planning a manufacturing system for moulds and dies.

(i) Core and punches which consist predominantly of convex surfaces; thus they can easily be machined by 3 -axes or 5 -axes milling. Cavities on the other hand may have deep pockets and/or surfaces that may be difficult to reach and generate by end mills. For this reason, EDM is often selected to finish machine cavities. Reconfigurability should be considered at the machine level, all the machines that will be put to use should be as reconfigurable as possible.

(ii) Material handling system must by bidirectional. Sometimes the reconfiguration requirement to perfectly accommodate production of a new product is just a change in the direction of the material handling system or in some other instances, an aid to easy reconfiguration.

(iii) Ample space should be provided around each of the machines to allow for future insertion of a bigger machine.

(iv) Aisles are to be made as wide as the available space in the factory can accommodate.

(v) A reconfigurable layout is a substantial aspect of a reconfigurable manufacturing system, therefore an AHP layout model proposed by Abdi [7] is recommended for layout selection.

\section{CONCLUSIONS}

Fluctuation in the market is a natural phenomenon which cannot be prevented or avoided but can only be absorbed. There are many theories in social sciences towards solving the problem, but nearly all of them will still come down to affecting the manufacturing system. The importance of mould and dies in the manufacture of parts therefore demands a prompt and efficient way of responding to its supply whenever the need arise. Therefore in a way to preparing for eventualities, incorporating reconfigurability in the design of our manufacturing system is of utmost importance. The paper, therefore, presents a holistic solution to the problem of sudden demand for a new set of mould and dies occasioned by market fluctuation. 


\section{ACKNOWLEDGEMENT}

The authors wish to acknowledge the financial commitment of AMTS (CSIR), Department of Science and Technology, Republic of South Africa to the course of the research work. We also wish to appreciate the support of the Department of Mechanical and Aeronautical Engineering, University of Pretoria, South Africa; the host of the research.

\section{REFERENCES:}

[1] T. Altan, Design and manufacture of dies and mould. CIRP Annals - Manufacturing Technology, Vol. 36, Issue 2 (1987), 455-462.

[2] R.K. Singh, N. Khilwani and M.K. Tiwari, Justification for the selection of a reconfigurable manufacturing system: a fuzzy analytical hierarchy based approach. Int. J. of Prod. Research, Vol. 45, No. 14 (2007), 3165-3190.

[3] R. Harrison, A.W. Colombo, A.A. West and S.M. Lee, Reconfigurable modular automation systems for automotive power-train manufacture. Int. J. of Flex. Man. Sys., Vol.18 (2006), 175190.

[4] G.H. Lee, Reconfigurability consideration design of components and manufacturing systems. Int. J. of Advanced Man. Tech., Vol.13 (1997), 376-386.

[5] H.P. Wiendahl, H.A. ElMaraghy, P. Nyhuis, M.F. Zäh, H.H. Wiendahl, N Duffie and M. Brieke, Changeable manufacturing - classification, design and operation. Annals of the CIRP Vol. 56, No1(2007), 786-809.

[6] Y. Koren, U. Heise, F. Jovane, T. Moriwaki, G. Pritschow, G. Usloy and V.H. Brussel, Reconfigurable manufacturing system. Keynote papers, Annals of the CIRP, Vol. 28, No. 2 (1999), 527-540.

[7] M.R. Abdi, Selection of a layout configuration for reconfigurable manufacturing system using the AHP. ISAHP 2005, Honolulu, Hawaii, July 8-10, 2005.

[8] A. Ahi, M.B. Aryanezhad, B. Ashtiani and A Makui, A novel approach to determine cell formation, intracellular machine layout and cell layout in the CMS problem based on TOPSIS method. Computer and Operational Research Vol. 36 (2009), 1478-1496.

[9] J. Ciurana, M.L. Garcia-Romeu, I. Ferrer and M. Casadesús, A model for integrating process planning and production planning and control in machining processes. Robotic and Computer-Integrated Manufacturing Vol. 24 (2008), 532-544.

[10] A. Azad and H.A. ElMaraghy, Sequential process planning: A hybrid optimal macro-level approach. Journal of Manufacturing Systems, Vol. 26 (2007), 147-160. 